\title{
DEBATE
}

\section{Outdoor smoking bans: more than meets the eye}

Simon Chapman argues that outdoor smoking bans are seldom justified because they can rarely be supported from a health standpoint, and they invite backlash from the community. We disagree. Rather, we believe that outdoor smoking bans are reasonable in a number of instances and that such bans can be justified for reasons other than health.

All should agree that, while indoor smoking bans are a higher priority, smoking bans are justified for health reasons in those outdoor environments which are similar to indoor environments in terms of their exposure to environmental tobacco smoke (ETS). Besides the crowded stadia example cited by Chapman, we would add outdoor entertainment facilities with assigned seating and other outdoor areas where smokers and non-smokers may have sustained, close contact. However, communities have chosen to ban smoking outdoors for many reasons besides health. This includes decreasing fire risk, controlling litter, and protecting residents from nuisances. In addition, health and medical facilities have unique reasons to ban outdoor smoking.

Cigarettes and other lighted tobacco products are the number one cause of fire deaths in the United States ${ }^{1}$ and, when improperly discarded in arid environments where fires are common, can pose a serious fire risk. For this reason, communities in California and elsewhere have banned outdoor smoking. ${ }^{2}$ Additionally, discarded cigarette butts can pose a significant litter burden, especially at recreational facilities such as beaches and parks. ${ }^{2} \mathrm{At}$ these facilities, smoking bans may be imposed, along with bans on glass bottles or picnicking. Such bans have the added effect of protecting infants and toddlers from ingesting tobacco from discarded cigarette butts. Some communities have banned smoking at outdoor facilities at schools and recreational centres in order to avoid presenting children and teenagers with adult role models who smoke, be they parents, visitors, coaches, teachers or staff. ${ }^{45}$

Communities also have the right to ban nuisances - things that are generally offensive, though not necessarily harmful-so long as fundamental individual liberties are preserved. In this regard, loud noise, billboards, public drinking and other activities are frequently regulated or banned entirely. Many people consider outdoor exposure to ETS an annoying nuisance and have pressed for bans in areas in which exposure cannot be easily avoided-such as at entrances to buildings. ${ }^{6}$ Should non-smokers who dislike ETS be required to tolerate it to preserve the "right" of those who smoke to satisfy their dependence? We think not.
Finally, medical and health facilities have unique needs and responsibilities. Ironically, these facilities were latecomers to the concept of smoking bans, to their discredit. Now, however, hospitals, physicians offices, clinics, health departments, and other medical/health facilities generally recognise that permitting smoking anywhere on their grounds is contrary to their mission to promote and protect health and compromises their integrity. Chapman argues that it is wrong to completely ban smoking on hospital grounds because doing so would force some patients to quit against their will and violate patient autonomy. But many patients are in the hospital for illnesses caused or exacerbated by their smoking! We believe it is wrong to allow patients to harm their health and interfere with their treatment while under medical supervision. Hospitals do not permit those confined to bed to walk the halls, or encourage patients on restricted diets to visit candy or soda machines. Neither should they allow patients who smoke to do so while hospitalised. Furthermore, it is reasonable, appropriate, and entirely justified to require patients' visitors to refrain from smoking while on hospital grounds.

Both indoor and outdoor smoking bans have the potential to generate criticism and backlash from those who do not understand our goals and from those who do not share them. Advocates must carefully assess community norms and standards before undertaking campaigns. But outdoor smoking bans have their place. MICHELLE BLOCH

Medical Officer,

Tobacco Control Research Branch,

National Cancer Institute,

Rockville, MD 20852, USA

Coordinator, Smoking and

DONALD R SHOPLAND

Tobacco Control Program,

National Cancer Institute,

Rockville, MD 20852, USA

1 US Consumer Product Safety Commission. Practicability of developing performance standard to reduce cigarette ignition developing performance standard to reduce cigarette ignition 1993.

2 Clayton, California. Ordinance no. 307. An ordinance of the city council prohibiting smoking in all sports facilities, both indoor and outdoor, parks, recreation areas and trails owned and maintained by the City of Clayton. Enacted 1993.

3 Sharon, Massachusetts. General By-laws, Article 10. Smoking of tobacco products at public playgrounds and the ing of tobacco products at public playgrounds and the
public beaches at Lake Massapoag is banned. Enacted public beacce 1995.

4 Barrington, Rhode Island. Ordinance 96-3. An ordinance prohibiting the use of tobacco products at athletic and recreational facilities owned by the town of Barrington during youth events. Enacted March 1996

5 State of Maryland. Tobacco Free Schools and Environment Regulation. COMAR 13A.02.04.

6 National Cancer Institute. State and local legislative action to reduce tobacco use. Smoking and tobacco control to reduce tobacco use. Smoking and tobacco control
monograph No. 11. Bethesda, MD: US Department of monograph No. 11. Bethesda, MD: US Department of Health and Hu
Health. In press. 